\title{
Experimental investigations of winglet effects on blade geometry of small horizontal axis wind turbine rotors
}

\author{
Manoj Kumar Chaudhary* and S. Prakash \\ Department of Mechanical Engineering, Sathyabama Institute of Science and Technology, Chennai, Tamilnadu, India. \\ * Corresponding Author: manojzf2011@gmail.com
}

Submitted :05/06/2020

Revised :23/02/2021

Accepted : :16/03/2021

\begin{abstract}
In this research work, the investigation and optimization of small horizontal axis wind turbine blade at low wind speed are pursued. The experimental blades were developed using the 3D printing additive manufacturing technique. The airfoils E210, NACA2412, S1223, SG6043, E216, NACA4415, SD7080, SD7033, S1210, and MAF were tested at the wind speed of 2-6 m/s. The airfoils and optimum blade geometry were investigated with the aid of the Xfoil software at Reynolds number of 100,000. The initial investigation range included tip speed ratios from 3 to 10 , solidity from $0.0431-0.1181$ and angle of attacks from $2^{\circ}$ to $20^{\circ}$. Later on, these parameters were varied in MATLAB and Xfoil software for optimization and investigation of the power coefficient, lift coefficient, drag coefficient, and lift to drag ratio. The cut-in wind speed of the rotors was 2 and $2.5 \mathrm{~m} / \mathrm{s}$ with the winglet-equipped blades and without winglets. It was found that the E210, SG6043, E216 NACA4415, and MAF airfoil displayed better performance than the NACA 2412, S1223, SD7080, S1210, and SD7003 for the geometry optimized for the operating conditions and manufacturing method described.
\end{abstract}

Keywords: Airfoils; Aerodynamic performance; Power coefficient; Solidity; Tip speed ratio.

\section{Nomenclature}

B: Number of Blade

$\alpha$ : Angle of attack
Cp: Power Coefficient

$\sigma:$ Solidity

\begin{abstract}
$\lambda$ : Tip Speed Ratio
$\rho$ : Density of Air.
\end{abstract}

\section{INTRODUCTION}

Wind turbines are classified in two categories, namely, the vertical-axis wind turbine (VAWT) and the horizontal-axis wind turbine (HAWT). Typically, VAWTs can generate more power at a relatively low wind speed than HAWTs. Therefore, it is more efficient to use VAWTs in residential areas. However, at the same wind speed, HAWT is expected to generate more power because the aerodynamic drag is less, and the rotation of all blades generates more wind power (Lee et al., 2016). Small wind turbines (SWTs) are typically designed to work within a wide range of wind speeds with no pitching control. Because of the specific area of utilization, SWTs preferably 
should have airfoils that can operate efficiently at low Reynolds numbers, self-start and produce energy at relatively low wind speeds, and have low maintenance costs. Furthermore, SWTs should be affordable, reliable, and maintenance-free for the average person to consider installing one. This often implies a tradeoff between optimal performance and simplicity in design and operation (Ismail et al., 2018). A horizontal-axis micro wind turbine requires a minimum wind speed of $4.2 \mathrm{~m} / \mathrm{s}$. Using the optimized blade could reduce the starting speed without external force, which enables its use in roadside or housetop applications (Abrar et al., 2014). Another wrok investigated the initial performance of small rotors and concluded that the torque-producing power was obtained mainly from the tip region of the blade (Wright and Wood, 2004; Clifton and Wood, 2007). A comparative study of various blade element models for the calculation of the local induced velocity and reported that the Blade element momentum (BEM) model offers excellent accuracy and high computational efficiency for propeller performance calculations (Gur and Rosen, 2008). Another work analyzed two-dimensional subsonic flow over a NACA 0012 and SG6043 airfoil at Reynolds number of $3 \times 10^{6}$ (Patel et al., 2014 and Chaudhary \& Prakash 2019). Another work studied the optimization of the distribution of chord and twist angles of small wind turbine blades to maximize their annual energy production. The pressure difference between the pressure and suction surfaces increases in the presence of winglets, and it was observed that the pressure difference increases with the increase in the winglet height or the decrease in the curvature radius of winglets. The winglet with height $4 \%$ of the rotor radius and the radius of curvature $25 \%$ of the winglet height resulted in higher pressure difference at the tip region of the blade, which could improve the power output (Hassanzadeh et al., 2016 and Saravanan et al., 2013). The Blades with five configurations of winglets were investigated; winglet height was changed from $1 \%$ to $5 \%$ of the wind turbine rotor with cant angle of $90^{\circ}$. The power coefficient can be improved by increasing the curvature radius of the winglet and the angle of the cant; from the results of the study, it is found that the sweep angle, cant angle, and twist angle have influenced the efficiency of the windmill to an average of $2 \%$ rise, the lifting coefficient, and 6\% decrease in the drag coefficient (Khaled et al., 2019 and Nataraj et al., 2019). Another work studied $2 \mathrm{~kW}$ small scale horizontal axis wind turbine with a rotor radius of $1.8 \mathrm{~m}$ and tip speed ratio (TSR) of 6 at low wind speed for rural applications, which was examined (Suresh and Rajakumar, 2019). The main objective of the present study is to investigate the MAF airfoil for use in small wind turbine at low Reynolds numbers. For the experimental investigations, wind tunnel experiments were performed to measure the power of 3-bladed rotor blades at various wind velocities and blade pitch angles. The rotor blade material used is acrylonitrile butadiene styrene (ABS) and fabricated by using the fused deposition method (FDM). The objectives of this paper can be listed as follows:

- Investigate the aerodynamic performance of E210, NACA2412, S1223, SG6043, E216, NACA4415, SD7080, SD7033, S1210, and MAF (mixed airfoil) airfoils at low Reynolds number.

- Experiment and numerically investigate small HAWT blades with and without winglets for different airfoils and blade solidity.

\section{MATERIAL AND METHODS}

The BEM method is one of the most popular approaches in the design of wind turbines. According to this theory, the axial and tangential forces acting on the turbine blade can be derived from two theories: Blade element theory and momentum theory. The maximum value for power coefficient of 0.593 is an ideal wind turbine. This value is called the Betz limit. Using Xfoil, a novel airfoil was developed in this study and used to optimize the blade shape of wind turbine with and without winglet.

\subsection{Calculation Procedure}

A summary of the Xfoil procedure for airfoil optimization and rotor blade geometry design is shown in Fig. 1. The blade geometry of the rotor experiment is shown in Fig. 2. BEMT is used in this study for aerodynamic design and optimization at low Reynolds number of a small wind turbine rotor blade by using Xfoil simulation. 
The Reynolds number (Re) of the airfoil essentially affects the aerodynamic performance of wind turbine, which was calculated from Eq. (1) [11].

$\operatorname{Re}=\frac{\rho V c}{\mu}$

$V$ is the relative wind velocity $(\mathrm{m} / \mathrm{s}), c$ is the chord length of airfoil $(m), \mu$ is the dynamic viscosity of a moving fluid $\left(\mathrm{N} s / \mathrm{m}^{2}\right)$,

The Solidity $(\sigma)$ of the airfoil essentially affects the aerodynamic performance of wind turbine is calculated from Eq. (2)

$\sigma=\frac{B \times C}{\pi R^{2}}$

where $B$ is the number of blade, $C$ is the blade area $\left(\mathrm{m}^{2}\right)$, and $R$ is the blade radius (m).

The Torque $(\mathrm{T})$ and turbine output power $(\mathrm{P})$ were calculated from Eq. (3- 4) as shown below:

$$
T=\frac{P}{\omega}
$$

$$
P=V I
$$

where $\omega$ is the angular velocity, $(\mathrm{rad} / \mathrm{s}), N$ is the rotor speed in rpm measured by laser tachometer, and I is the rotor voltage and current. $\mathrm{V}$ and I are measured by the voltmeter at different wind speed.

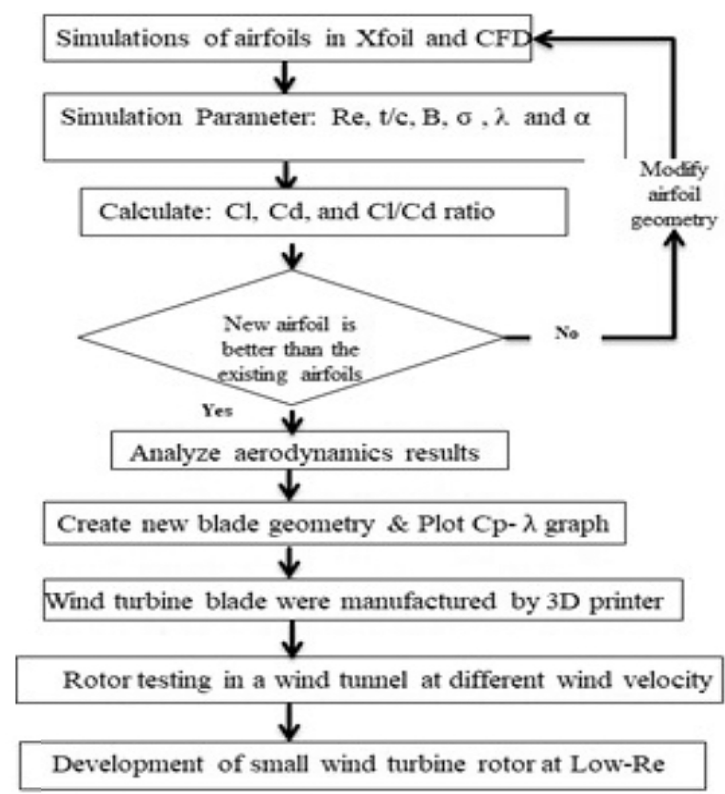

Figure 1. Summary of Xfoil procedure for airfoil and blade design. 


\section{EXPERIMENTAL METHOD}

\subsection{Blade Geometry Optimization with and Without Rotor Winglet}

The geometry shapes of different rotor are depicted in Fig. 2. The small wind turbine blade for a rotor with optimal TSR $=4-7$, which was manufactured using the PLA material, was studied for optimization. The blade radiuses were $0.2 \mathrm{~m}$ with and without winglet, respectively, by using the new airfoil. Figure 4 depicts the variations of the chord and twist angle with sectional blade length at various rotors $(R 1, R 2, R 3$, and $R 4)$ for new airfoil $B=3$ without and with winglet rotors. The winglet angle was considered to be $70^{\circ}$, and winglet height was $1.5 \mathrm{~cm}$ with variable chord. The maximum and minimum chords were $0.026 \mathrm{~m}$ and $0.018 \mathrm{~m}$ when the twist angle was $14.89^{\circ}$ at the root and $1.29^{\circ}$ at the tip with winglet $R 2$ rotor; similarly, the maximum and minimum chords were $0.047 \mathrm{~m}$ and $0.032 \mathrm{~m}$ when the twist angle was $23.17^{\circ}$ at the root and $3.98^{\circ}$ at the tip without winglet $R 4$ rotor. Figure 4 illustrates the optimum blade geometry designed at the Solidity $=4.31-11.81 \%$, for rapid prototype fabrications. It was seen that the chord length and twist angle decreases when the length of the blades is increased. The cost and difficulty of fabrication increases with the increase in the twist angle; therefore, the maximum twist angle was set to $40^{\circ}$. The R1, R3, and R4 rotor were without winglet; however, R2 rotor was winglet shape of blade geometry. Solidity of rotor is $0.043,0.06,0.0726$, and 0.1181 for rotors R1, R2, R3, and R4.

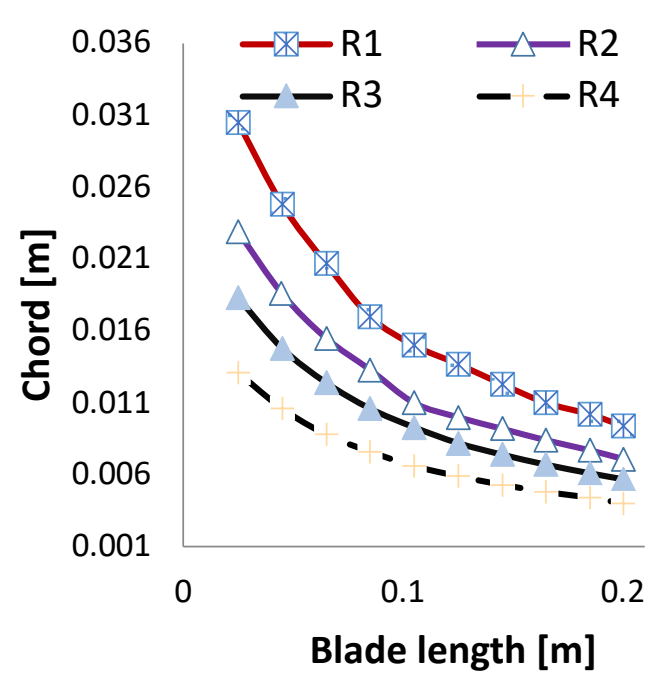

(a)

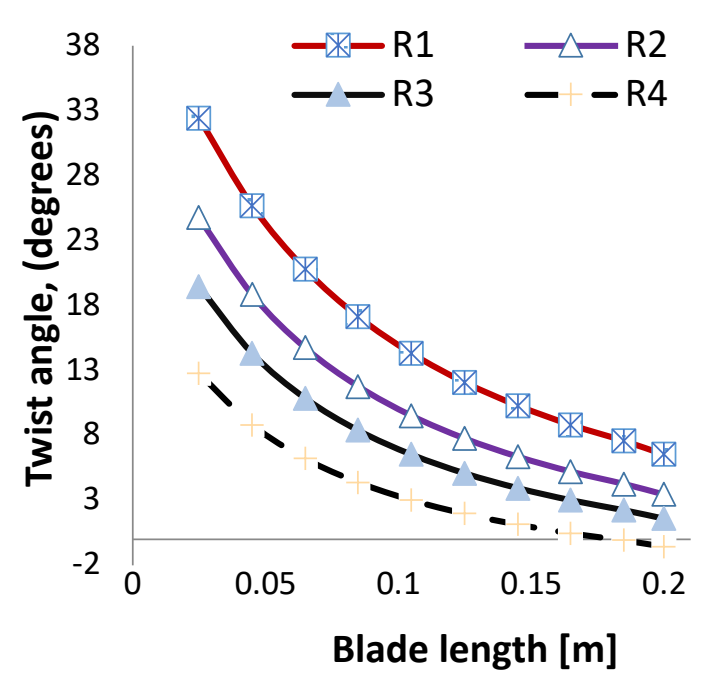

(b)

Figure 2. Blade geometry. (a) Chord versus blade length. (b) Twist angle versus blade length.

\subsection{Fabrication of Small Wind Turbine Rotor Blade}

The small wind turbine blade geometries as depicted in Fig. 2 were fabricated by 3D printing (Additive manufacturing), with the PLA filaments. The Creo models were transformed from the format into G code using Cura software and imported to the $3 \mathrm{D}$ printer. The printer was run under the following conditions; printing resolution was set to $0.001 \mathrm{~m}$, nozzle temperature was adjusted to $205^{\circ} \mathrm{C}$, and bed temperature was $60{ }^{\circ} \mathrm{C}$. Figure 3 shows the Blade analysis and tests stands of four wind turbine model used in the experiment. The centrifugal fan's 
motor was 3-phase 440 Volt AC supply, the air velocity was varied from 3 to $30 \mathrm{~m} / \mathrm{s}$ with the help of controller, and a 7-blade blower fan with $5.59 \mathrm{kw}$ electric motor, $1500 \mathrm{rpm}$, and excitation voltage $200 \mathrm{Volt}$ DC was used. The tunnel has a test section of $0.3 \mathrm{~m} \times 0.3 \mathrm{~m} \times 1 \mathrm{~m}$. The HTC anemometer could measure wind speeds from $1 \mathrm{~m} / \mathrm{s}$ to $30 \mathrm{~m} / \mathrm{s}$. Model 560 digital tachometer has the following characteristics: Model: HTM-560, resolution range: 0.1 to $1000 \mathrm{rpm}$, basic accuracy: $\pm 0.05 \%$ reading +1 digit, measuring distance: 0.075 to $0.3 \mathrm{~m}$, and operating temperature: 0 to $60^{\circ} \mathrm{C}$. The experimental set up is depicted in Fig. 4 .

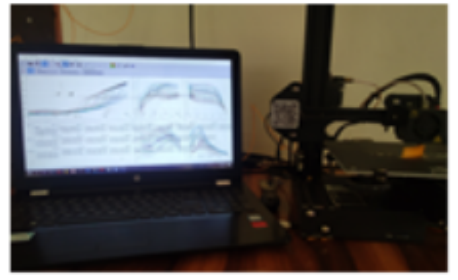

(a)

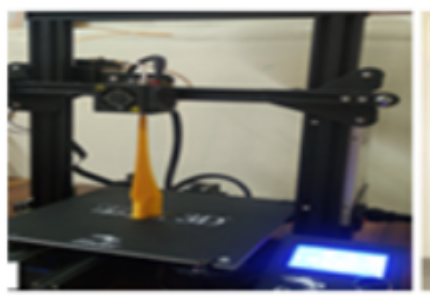

(c)

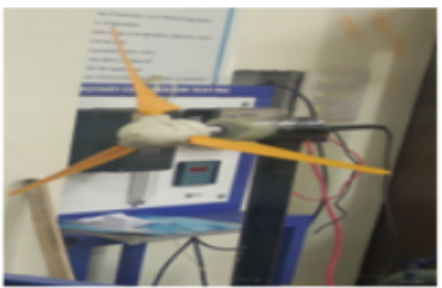

(a)

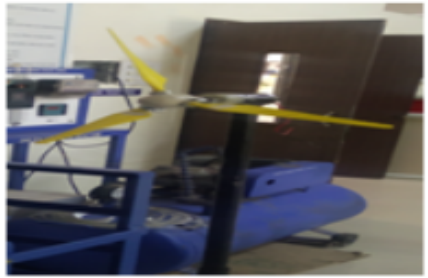

(c)

(i)

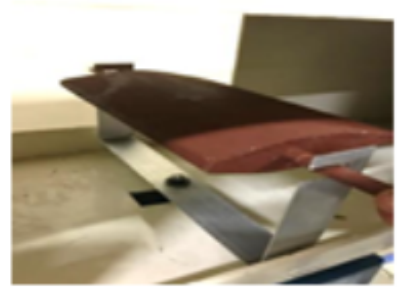

(b)

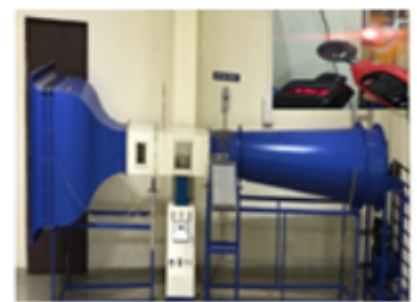

(d)

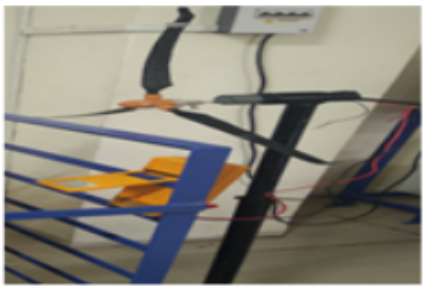

(b)

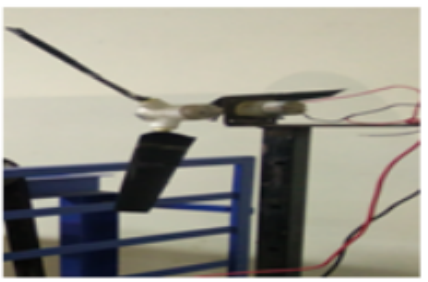

(d)

(ii)

Figure 3. Blade analysis and fabrication [i]. (a) Airfoil simulation in Xfoil software. (b) New airfoil (wooden material). (c) Blade fabrications by 3D printer (PLA material). (d) Experimental test rig. [ii] 3D printed wind turbine rotors of different solidity: (a) R1; (b) R2; (c) R3; (d) R4. 


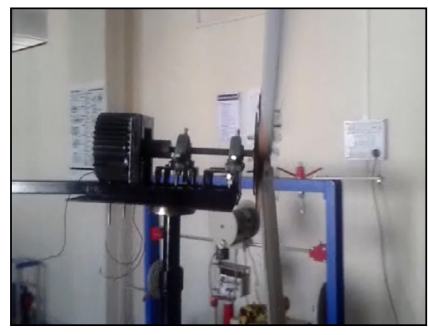

(a)

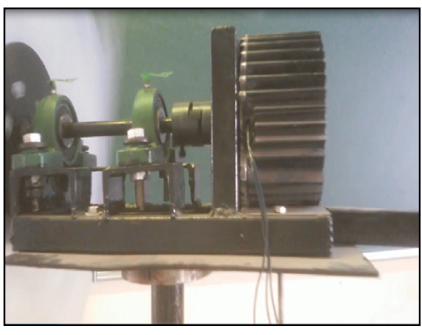

(b)

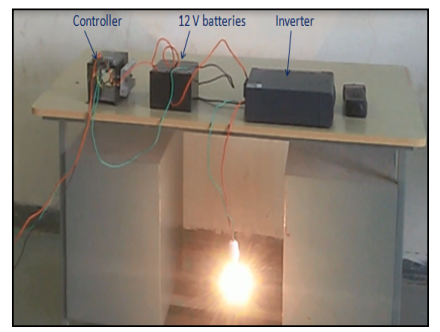

(c)

Figure 4. Experimental setup: (a) shaft coupling arrangement; (b) alternator; (f) inverter.

\section{RESULTS AND DISCUSSION}

The results of the numerical and experimental investigations for all cases are presented in this section. Experimental cases of wind turbine rotor with wind velocity from the cut-in speed $(2 \mathrm{~m} / \mathrm{s})$ to the rated wind speed $(6 \mathrm{~m} / \mathrm{s})$ and the configurations of the rotor solidities of $4.31 \%$ to $11.81 \%$ were analyzed for blade number of 3 with and without winglet. The maximum values of power coefficient of rotor for different airfoils and solidity are given in Table 2 at Reynolds number $=100,000$

\subsection{Comparison of MAF Airfoil with other Airfoils Application for Small Wind Turbine Blades}

The aerodynamics performance comparison of the MAF airfoil with E210, NACA2412, S1223, SG6043, E216, NACA4415, SD7080, SD7003, and S1210 airfoil in Xfoil results is depicted in Figs. 5(a-b). The airfoils were tested with Xfoil at $\mathrm{Re}=100,000$ and Ncrit=2.5. Figs. $5(\mathrm{a}-\mathrm{b})$, as shown in the graphs of lift and lift-to-drag ratio for the 10 airfoils at $\mathrm{Re}=100,000$. From Fig. 5(a), it was observed that the lift coefficient values are strongly influenced by the angle of attack $(\alpha)$. From the results graph, it can be observed that mixed airfoil (MAF) airfoil ranks second to S1223 airfoil, which has the highest lift coefficient values in the angle of attack ranges of 2-12 . From the graph, it can be observed that $\mathrm{S} 1223$ and MAF airfoil produce maximum $\mathrm{C}_{\mathrm{L}}$ of 2.09 and 1.9 at angle of attack, $\alpha$ of $12^{\circ}$, respectively. S1210 airfoil produces maximum $C_{L}$ of 1.8 at $\alpha$ of $14^{\circ}$. After $12^{\circ}$ angle of attack, the value of $C_{L}$ for $\mathrm{S} 1123$ and MAF airfoil decreases up to angle of attack, $\alpha=16^{\circ}$ beyond $16^{\circ}$ angle of attack; the value of $\mathrm{C}_{\mathrm{L}}=1.8$ remains constant up to $20^{\circ}$ angle of attack. Airfoils S1210, E216, E210, and NACA4415 have maximum $\mathrm{C}_{\mathrm{L}}$ of $1.83,1.5,1.32$, and 1.32 at angle of attack, $\alpha$ of $12^{\circ}$. Similarly, SD7003 and SD7080 produced maximum $\mathrm{C}_{\mathrm{L}}=1.18$ and 1.18 at $\alpha$ of $12^{\circ}$, respectively, while $\mathrm{SG6043}$ airfoil produced maximum $\mathrm{C}_{\mathrm{L}}=1.51$ at angle of attack, $\alpha$ of $14^{\circ}$. The airfoils MAF, S1210, E216, NACA4415, and SG6043 showed soft stall behavior in the angle of attack range of $12-16^{\circ}$. Fig. 5(b) shows the variation of lift-to-drag ratio $\left(\mathrm{C}_{\mathrm{L}} / \mathrm{C}_{\mathrm{D}}\right)$ for different airfoils at a low Reynolds number $=100,000$. Maximum lift-to-drag ratios $\left(C_{L} / C_{D}\right)$ of 67.35 were produced by E216 airfoil at $\alpha$ of $4^{\circ}$ followed by S1210 and SG6043 airfoil of 66.16 at $\alpha$ of $6^{\circ}$, respectively. Airfoils MAF, S1223, E210, SD7080, NACA4415, NACA2412, and SD7003 have maximum lift-to-drag ratio $\left(\mathrm{C}_{\mathrm{L}} / \mathrm{C}_{\mathrm{D}}\right)=62.22,58.13,56.4,51.7,51.7,48.88$, and 45.06, respectively, at $\alpha=6^{\circ}$. The SD7003 and NACA2412 airfoils produced lowest values of $\mathrm{C}_{\mathrm{L}} / \mathrm{C}_{\mathrm{D}}$ ratios of 33.2 and 34.48 at angle of attack, $\alpha=2^{\circ}$ and $\alpha=10^{\circ}$, respectively. Finally, from the obtained results of Xfoil, it was found that the E216, SG6043, NACA2412, E210, and S1223 airfoils had their peak values of lift-to-drag ratios producing at particular $\alpha$ value, while MAF, S1210, SD7080, NACA44515, and NACA4415 airfoils had a wide range of $\mathrm{C}_{\mathrm{L}} / \mathrm{C}_{\mathrm{D}}$ ratios and showed a soft stall behavior in the angle of attack, $\alpha$ range of $4^{\circ}-8^{\circ}$. 


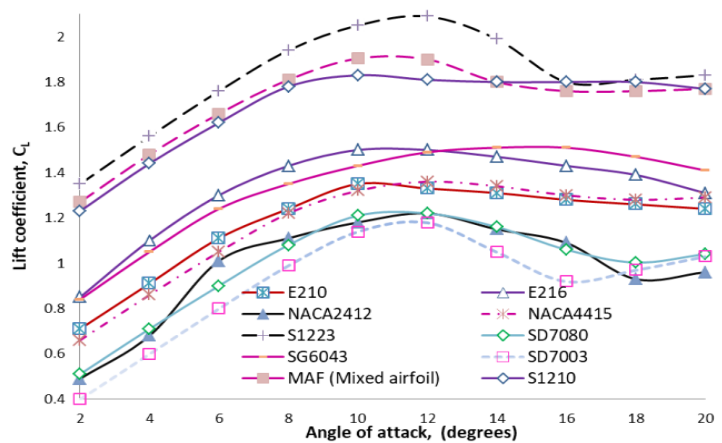

(a)

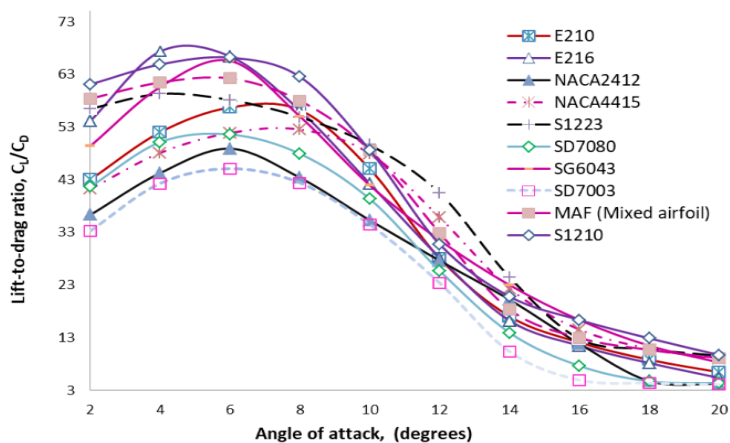

(b)

Figure 5. Variations of (a) lift coefficient $\left(\mathrm{C}_{\mathrm{L}}\right)$, (b) lift-to-drag ratios $\left(\mathrm{C}_{\mathrm{L}} / \mathrm{C}_{\mathrm{D}}\right)$ of different airfoils at Reynolds number $=100,000$.

It was seen that the MAF airfoil is the best profile for small horizontal axis wind turbines al low Reynolds number application. The maximum value of the $\mathrm{C}_{\mathrm{L}} / \mathrm{C}_{\mathrm{D}}$ ratio for the studied airfoil was observed at an $\mathrm{AOA}$ of $5^{\circ}$ to $6^{\circ}$ at Reynolds number $=100,000$

\subsection{Effect of the Airfoil and Tip Speed Ratio on Power Coefficient at $\sigma=\mathbf{0 . 0 4 3 1}$}

The BEMT-based design program was developed for tip speed ratios ranging from 2 to 8 . The $\mathrm{Cp}-\lambda$ curve was obtained using Xfoil software. The solidities of $4.31 \%$ to $11.81 \%$ with variable chord and twisted blade geometry were analyzed at $\mathrm{Re}=100,000$ of various low-Re airfoils for blade numbers 3, and the results are illustrated in Fig. 6 (a-d). From Fig. 6(a), it can be observed that the $\mathrm{Cp}$ values increase with a maximum tip speed ratio of up to 7 for rotor R1 of solidity $=4.31 \%$ and then decrease with the exception of airfoil S1223 and S1210. Figure 6(a) shows that R1 rotor, such as airfoils E210, E216, SG6043, NACA2412, NACA 4415, SD7080, SD7003, and MAF, has the maximum $C p=0.43,0.46,0.38,0.42,0.39,0.37$, and 0.44 at $\lambda=7$, but the maximum $\mathrm{Cp}=0.45$ and 0.46 are produced by the R1 rotor, such as airfoils S1223 and S1210. From the results of the analysis, E216, SG6043, NACA4415, and MAF (New Airfoil) were found to be optimal for small horizontal axis wind turbines due to their wide range of 5-7 tip speed ratios at Solidity $=4.31 \%$.

\subsection{Effect of the Airfoil and Tip Speed Ratio on Power Coefficient at $\sigma=\mathbf{0 . 0 6 0 4}$}

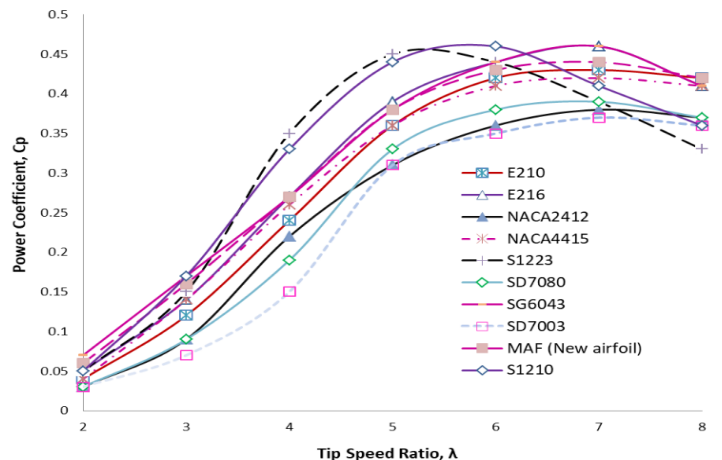

(a)

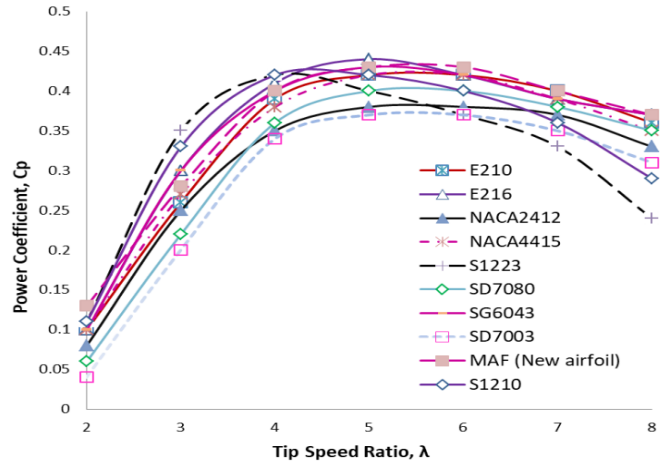

(b) 


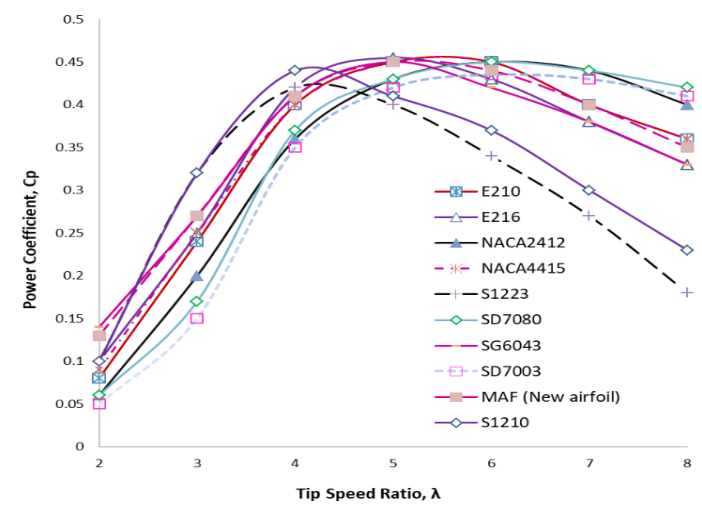

(c)

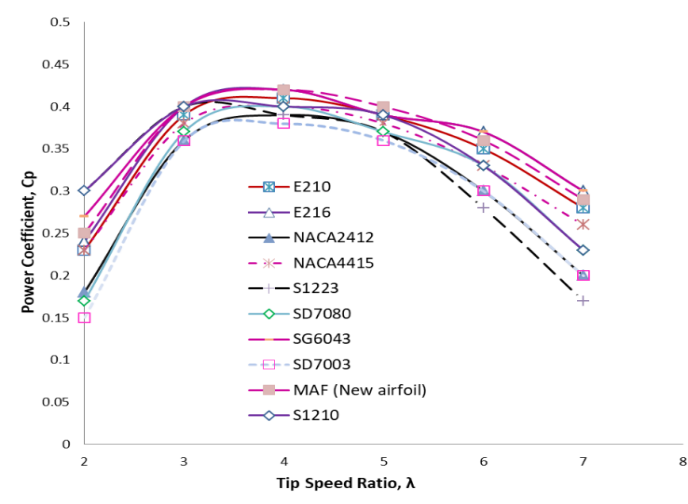

(d)

Figure 6. Power coefficient versus tip speed ratio at $\mathrm{Re}=100,000$ for different airfoils rotors

(a) R1, (b) R2, (c) R3, (R4).

Fig. 6(b) displays the power coefficient of the different rotor $R 2$ airfoils with winglet blade geometry at solidity $=6.04 \%$. From the graphical representation, the BEMT- $R 2$ rotor, such as the airfoils E210, NACA 2412, SG6043, E216, NACA4415, SD7080, SD7003, and MAF, has the maximum $C p=0.42,0.38,0.43,0.44,0.42,0.4$, 0.37 , and 0.43 at $\lambda=5$, while the values of maximum $C p=0.42$ and 0.42 for S1223 and S1210 airfoil at tip speed ratios $\lambda=4$, respectively. Finally, the airfoils simulation results showed that E210, SG6043, E216, NACA4415, and MAF of the BEMT-R2 rotor were the most suitable for wind turbine blades due to their large range of tip speed ratios, $\lambda=4$ to 6 at Solidity $=6.04 \%$.

\subsection{Effect of the Airfoil and Tip Speed Ratio on Power Coefficient at $\sigma=0.0726$}

Fig. 6(c) shows the power coefficient of rotor $R 3$ of different airfoils at Solidity $=7.26 \%$ without winglet blade geometry. It can be seen from Fig. 6 (c) that $R 3$ rotor, such as airfoils E210, SG6043, E216, NACA4415, and MAF, has the maximum $\mathrm{Cp}=0.45,0.45,0.455,0.45$, and 0.45 at $\lambda=5$, but R3 rotor, such as airfoils NACA2412, SD7080, and SD7003, produces the maximum $C p=0.45,0.45$, and 0.435 , while airfoils S1223 and S1210 generate the maximum $\mathrm{Cp}=0.42$ and 0.44 at the tip speed ratio $\lambda=4$, respectively. Finally, from the numerical simulations, BEMT-R3 rotor, such as NACA2412, SD7080, SD7003, and MAF, was best suited for wind turbine blades due to their wide range of tip speed ratio, $\lambda=4$ to 7 at solidity $=7.26 \%$.

\subsection{Effect of the Airfoil and Tip Speed Ratio on Power Coefficient at $\sigma=0.1181$}

Fig. 6 (d) shows the power coefficient of different airfoils of rotor R4 at solidity $=11.81 \%$ without winglet blade geometry. Fig. 6(d) shows that R4 rotor, such as airfoils E210, NACA2412, S1223, SG6043, E216, NACA4415, SD7080, SD7003 S1210, and MAF, has the maximum $C p=0.4,0.41$ and $0.39,0.42,0.42,0.4,0.4$, $0.4,0.38$, and 0.42, respectively. Finally, from the numerical simulations, the BEMT-R3 rotor, such as E216, SG6043, and MAF, was the most suitable for wind turbine blades due to its wide range of tip speed ratio, $\lambda=3$ to 5 at solidity $=11.81 \%$. Finally, it was inferred from the $\mathrm{Cp}-\lambda$ graph that MAF airfoil, BEMT-blade, was selected for small wind turbines because of its large range of tip speed ratios, $\lambda$ from $4-7$ for a solidity, $\sigma$ range of $4.31 \%$ to $11.81 \%$. 


\subsection{Performance Testing of R1, R2, R3, and R4 3D Printing by Using MAF Airfoil}

The experimentation results of variation in the wind speed at optimum blade pitch angle of $22^{\circ}$ are depicted in Fig. 7 (a-b). The torque values increased with the rise in turbine rotor solidity are shown in Fig. 7(a); however, the $R 2$ and $R 3$ rotors with and winglet blade geometry generate approximately equal torque up to rated wind speed, the maximum torque produced by R3- rotor. It has been found from graphical representations that the winglet geometry blade produces greater torque compared to the rotor without winglet, with lower power. Torque and power are calculated from equations 3 and 4 at various wind speeds. Figure 7(b) depicts the output power of wind speed variable rotors. The R3 rotor generates maximum power at a wind speed from $2.5 \mathrm{~m} / \mathrm{s}$ to $6 \mathrm{~m} / \mathrm{s}$ compared to the $R 1$, $R 2$, and $R 3$ rotors. It can be observed from the results graph that winglet rotor $\mathrm{R} 2$ ranks second to $\mathrm{R} 4$ rotor, which has the highest output power in the $2-6 \mathrm{~m} / \mathrm{s}$ wind speed range. The winglet R2 rotor produces more power in the wind speed range of 5-6 m/s compared to the rotor R2 equipped without winglet at approximately the same solidity. The percentage of error propagations was approximately $80-85 \%$. The difference between the experimental results and Xfoil results approximate was $20 \%$ to $30 \%$. Xfoil results values were higher than experimental results.

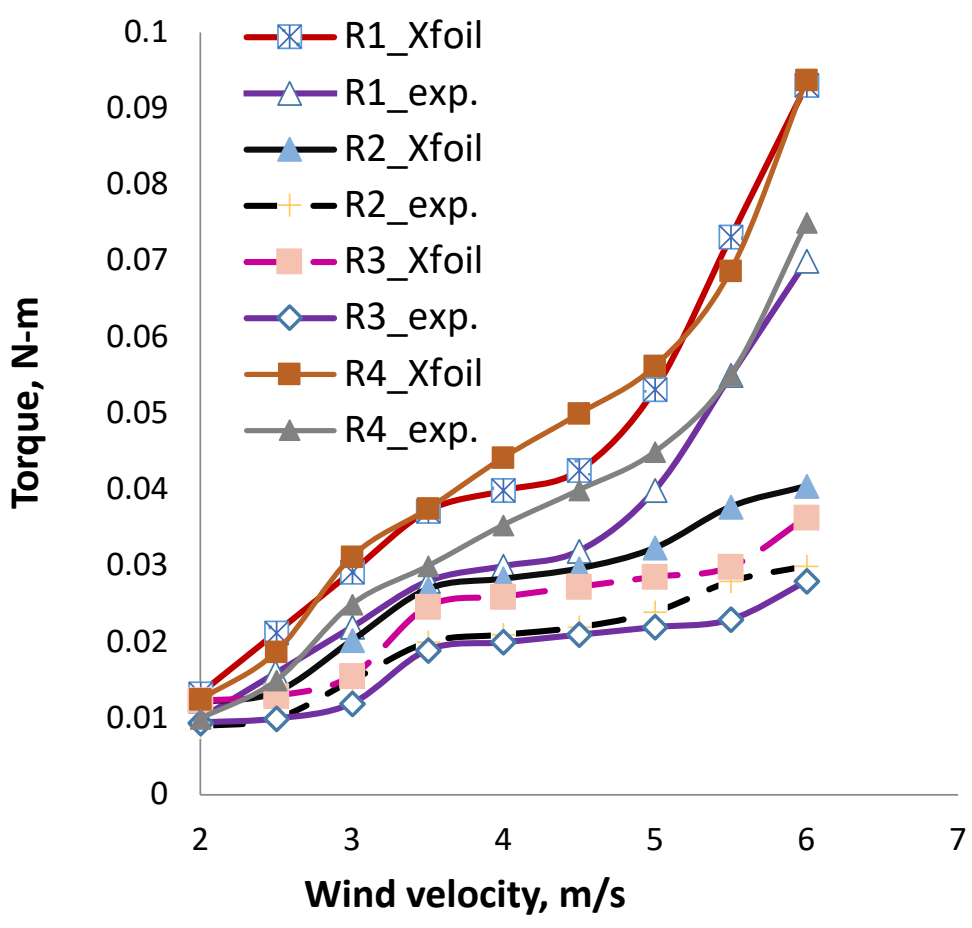

(a) 


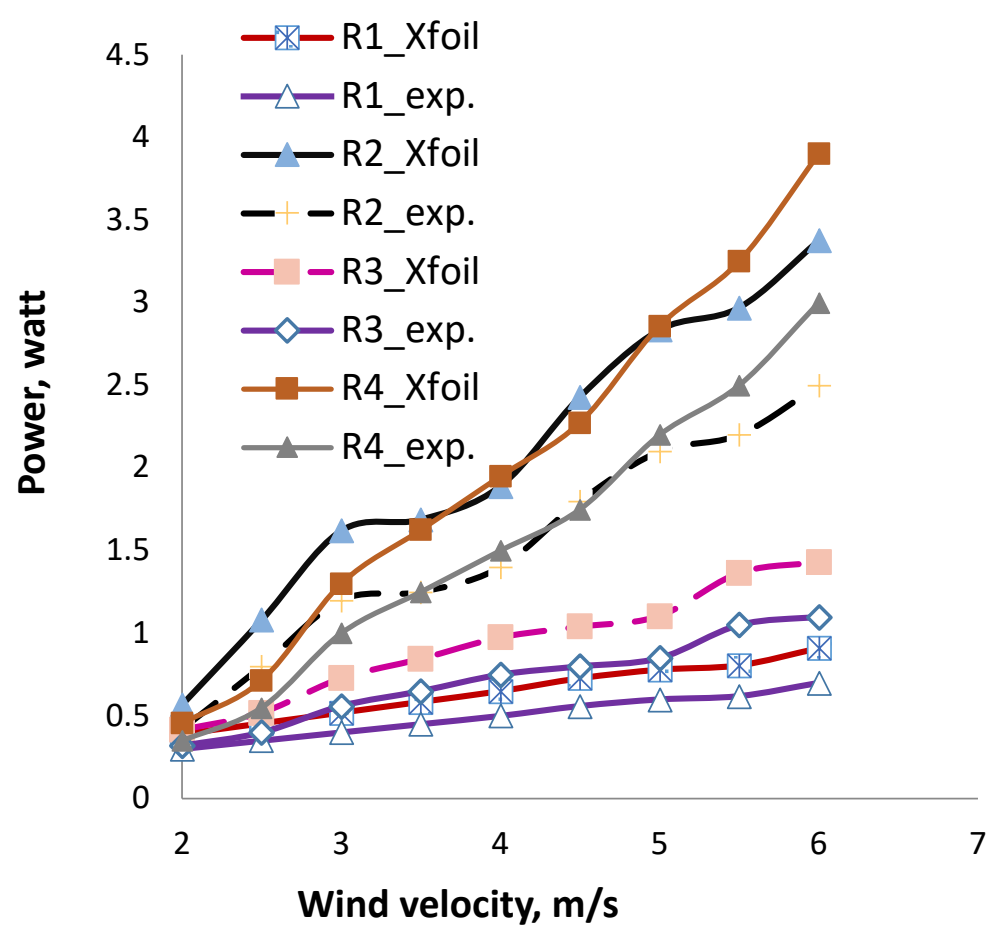

(b)

Figure 7. (a) Torque distribution of the R1, R2, R3, and R4 rotors with new airfoil blade section. (b) Power distributions of the R1, R2, R3, and R4 rotors at different wind speed.

\section{CONCLUSIONS}

This paper presents a new airfoil proposed to operate with a low Reynolds number. The MAF airfoil has been optimized through Xfoil from existing low Reynolds number airfoils E210, NACA2412, S1223, SG6043, E216, NACA4415, SD7080, SD7033, and S1210. In this paper, 10 low Reynolds number airfoils have been investigated at Reynolds number $=100,000$. It can be concluded that MAF, S1210, and SG6043 airfoils were the most suitable for small horizontal axis wind turbines at low Reynolds number application due to their maximum range of soft behavior compared to other airfoils. The numerical and experimental results showed that MAF was the airfoil most suitable for obtaining maximum power at low Re values. 3-bladed and $0.2 \mathrm{~m}$ blade radius of four BEMT-based test models were made additive manufacturing from PLA material for experimentation investigations. The four rotors with a solidity range of $0.0431-0.1181$ were designed and manufactured. Three rotors $(R 1, R 3$, and $R 4)$ were designed without winglet blade geometry of MAF airfoil cross section and winglet-equipped $R 2$ rotor. The blade geometries of the ten airfoils were optimized with regard to tip and root losses, based on the blade element momentum theory (BEMT). The power coefficient $(C p)$ for the selected and new airfoil (MAF) airfoils was varied in relation to the tip speed ratio $(\lambda)$. From the results of the simulation, it was found that the MAF airfoil blade has an optimum power coefficient of $C p=0.44$, for Reynolds number $(\mathrm{Re})=100,000$ for solidity $=0.0431$ without winglet at $\lambda=7$. The MAF airfoil blade has a maximum power coefficient of 0.43 and 0.45 at $\lambda=5$, produced at the solidity $=0.0604$ and 0.0726 for $\operatorname{Re}=100,000$, respectively. The maximum power coefficient was approximately 0.42 at $\lambda=4$, at solidity $=0.1181$. It was therefore inferred from the numerical simulation that MAF airfoil was the most suitable airfoil for producing maximum power in applications with low wind speeds. It has been confirmed 
that winglet blade geometry is more efficient at rotor solidity below $10 \%$, while without winglet blade geometry good rotor efficiency is produced at solidity range between $7 \%$ and $12 \%$. The higher solidity produces high torque with a low tip speed ratio of 4-5 and gives better starting performance to the rotors. The geometry of the airfoil directly influences the performance of the rotor and the tip speed ratio when the blade is designed with solidity below $12 \%$. The theoretical and experimental results suggest that the geometry of the rotors $R 4$ and $R 2$ is more suitable for small horizontal axis wind turbines at low wind speed applications.

\section{REFERENCES}

Abrar, M. A., Mahbub, A. M. \& Mamun, M. 2014. Design Optimization of a Horizontal Axis Micro Wind Turbine through Development of CFD Model and Experimentation, $10^{\text {th }}$ International Conference on Mechanical Engineering Procedia, Engineering, 90: 333-338.

Chaudhary, M K, and Prakash, S. 2019. Investigation of Blade Geometry and Airfoil for Small Wind Turbine Blade, American Scientific Publishers 11(5): 448-452.

Clifton-Smith, M.J. \& Wood, D. H. 2007. Further dual purpose evolutionary optimization of small wind turbine blades, J. Phys. Conf. Ser., 75: 012017

Gur, O. \& Rosen, A. 2008. Comparison between blade-element models of propellers. Aeronaut J.112:689-704

Hassanzadeh, A., Hassanabad, H.H. \& Dadvand, A. 2016. Aerodynamic shape optimization and analysis of small wind turbine blades employing the Viterna approach for post-stall region, Alexandria Engineering Journal. 55 (3): 2035-2043.

Ismail, A.R.K., Thiago, Canale. \& Fatima, A.M. Lino. 2018. Parametric analysis of Joukowski airfoil for10$\mathrm{kW}$ horizontal axis windmill, Journal of the Brazilian Society of Mech. Sciences and Engineering. 40, Article no: 179.

Khaled, M., Ibrahim, M. M., Hamed, A. H., and Ahmed, F. 2019. Investigation of a small Horizontal Axis wind turbine performance with and without winglet, Energy, 187:115921.

Lee, M.H., Shiah, Y.C. \& Chi Jeng, B. 2016. Experiments and numerical simulations of the rotor- blade performance for a small-scale horizontal axis wind turbine, J. Wind Eng. Ind. Aerodynamics.149: 17 - 29

Nataraj, M., and Balaji, G. 2019, Study on performance of wind mill by adding winglet in turbine blade: Virtual analysis, Journal of scientific \& industrial research,78:96-101.

Patel, K. S., Pate, S. B., Patel, U. B., and Ahuja , A. P., 2014, "CFD Analysis of an Aerofoil” International Journal of Engineering Research, 3: 154 - 158.

Suresh, A. \& Rajakumar, S. 2019. Design of small horizontal axis wind turbine for low wind speed rural application, Material today proceeding.23 (1):16-22

Saravanan, P., Parammasivam, K., and Rajan, S. 2013. Experimental Investigation on Small Horizontal Axis Wind Turbine Rotor Using Winglet, Journal of Applied Science and Engineering, 16 (2):159-164.

Wright, A.K. \& Wood, D.H. 2004. The starting and low wind speed behaviour of a small horizontal axis wind turbine, Journal of Wind Engineering and Industrial Aerodynamics. 92:1265-1279 